"summoning up, in choice symbols, the collective psyche of our time.".

But the opera is also pertinent to issues that often arise in Nature's pages. The application of science is ever more extended into the workings of the world and is all the more capable of instilling distrust in the society that pays for it. We should expect non-scientists to be wary of a profession that is often as excited, driven and single-mindedly focused as the Manhattan Project scientists.

The end of the opera should leave receptive audiences more aware of the case for scientists engaging with the public. The opera is framed at the beginning and end of each act by electronic soundscapes. The last moments take us beyond the Trinity test to the voice of a Japanese woman begging for water. This is not only a fitting reference to the ethical question that overshadows the opera, but also a reflection of the societal challenge facing any scientist or technologist today whose research could change peoples lives. Scientists still face equivalent moral debates of expediency (is the work justified by the benefits?) and of fundamental principle (is it in opposition to humanity's deepest values and hence to be forbidden?). They can choose to lock themselves away or consider the full implications of what is being achieved and reach out.

The efforts of leading scientists such as Robert Wilson and Leo Szilard to engage with decision-makers over Hiroshima, however debatable, should inspire us today. Adams' opera has helped them to do so in a way that no conventional history can. His music really is necessary.

Philip Campbell is editor-in-chief of Nature.

\title{
Mathematical musings
}

\section{Euclid in the Rainforest: Discovering \\ Universal Truth in Logic and Math \\ by Joseph Mazur \\ Pi Press: 2005.352 pp. $\$ 14.95, \notin 10.99$}

\section{Timothy Gowers}

Euclid in the Rainforest by mathematician Joseph Mazur is difficult to summarize, as its title perhaps suggests, but here is an attempt. Mazur's central theme is reasoning, both mathematical and scientific, and he divides it into three kinds. First he discusses simple syllogistic reasoning of the kind made systematic by Aristotle, of which the most famous example is the following deduction: all men are mortal; Socrates is a man; therefore, Socrates is mortal.

Next, he shows that this sort of logic is not powerful enough to deal with an essential part of mathematics: the infinite. For thousands of years, mathematicians had to rely on intuition and common sense when, for instance, they

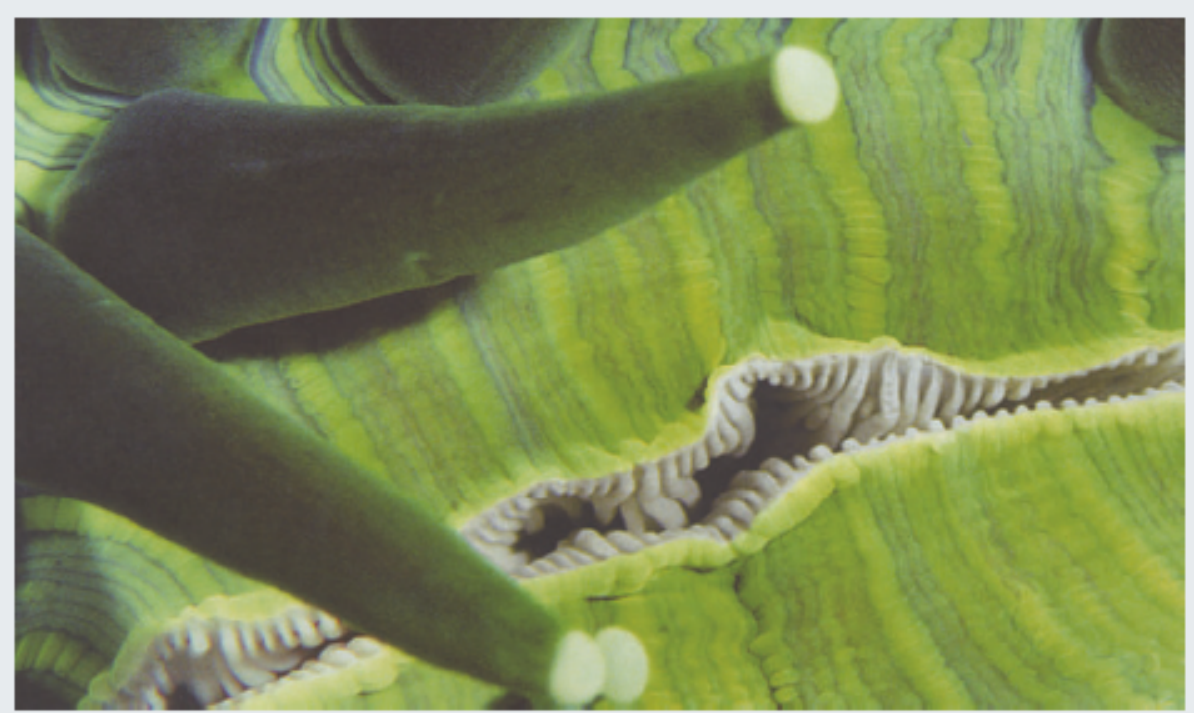

which seems to have been very interesting from time to time one wonders whether he has partly fictionalized it. He then lets his preoccupations emerge, much as a novelist might.

If you are interested in different forms of reasoning and are looking for a systematic treatment, this book is not the place to find it. For instance, bayesian analysis has a lot to say about plausible reasoning, but Thomas Bayes is mentioned only once, very briefly, in the introduction. Instead, this book is more like a fascinating conversation that stays within certain bounds but nevertheless often moves in unexpected directions.

For example, Mazur discusses, and clearly cares deeply about, a technique called 'facilitative communication, which allegedly allows severely autistic children to communicate with the help of a trained intermediary. Sceptics, of whom Mazur is one, ask why we should believe that messages that result from the technique come from the child, rather than the intermediary - a question of some importance, because evidence based solely on facilitative communication has been used to send parents to jail for sexual abuse. The reader is not offered a general method for deciding whether or not a statement is plausible, but the examples that bubble up from the narrative are thought-provoking in many ways.

These qualities make Eudid in the Rainforest an unusual book. It even contains, briefly and tastefully, a sex scene, which is probably a first for a popular mathematics book. There are also a few spelling mistakes (for instance, the playwright David Auburn, the philosopher Carl Hempel and Bleecker Street are all misspelled), but these contribute to the conversational feel of the book - as if it's the sound that really matters - and add to its charm. Rather than trying to extract general conclusions from the book, the best approach is simply to relax and enjoy the company of its author.

Timothy Gowers is at the Centre for Mathematical Sciences, University of Cambridge, Wilberforce Road, Cambridge CB3 OWB, UK.

\section{Up close and colourful}

Coral reefs are fascinating places. Marine biologists are still seeking to und erstand the complexity of life within these ecosystems, which also provide a valuable physical barrier, protecting coas ts from storm surges. Many divers will have found impres sive coral formations and wondered at the colourful fish and crustaceans that inhabit these rich habitats. But few will have ever noticed the subtle variations in colour shown in this photograph of an anemone coral, as the coral polyps emerged atnight. In Another World (ACC Books, E29.50), photographer Dos Winkel has brought an ar tist's eye to capture the diversity of colours and textures found on coral reefs. 